\title{
Diffusion Measurements with the Gravimetric Method in Solutions and in Molten Alkali Nitrates
}

\author{
F. van der Graaf* and J. A. A. Ketelaar** \\ Van't Hoff Institute of Chemistry, The University of Amsterdam, The Netherlands
}

Z. Naturforsch. 39a, 247-253 (1984); received December 23, 1982

\begin{abstract}
The gravimetric method of interdiffusion measurement from a quartz frit is developped into an accurate general method. It is applied to a number of electrolyte solutions; for iodides and bromides a correction for the adsorption is applied. For the molten alkali nitrate systems $(\mathrm{K}-\mathrm{Cs}) \mathrm{NO}_{3}$ at the molar fractions $x_{\mathrm{Cs}}=0.0$ and $x_{\mathrm{Cs}}=0.1,(\mathrm{Na}-\mathrm{Cs}) \mathrm{NO}_{3}$ at $x_{\mathrm{Cs}}=0.0$ and $x_{\mathrm{Cs}}=0.1,(\mathrm{Na}-\mathrm{Rb}) \mathrm{NO}_{3}$ at $x_{\mathrm{Rb}}=0.0$ and $x_{\mathrm{Rb}}=0.1$ and $(\mathrm{Na}-\mathrm{K}) \mathrm{NO}_{3}$ at $x_{\mathrm{Na}}=0.0, x_{\mathrm{Na}}=0.3$ and $x_{\mathrm{Na}}=1.0$ the interdiffusion coefficient is determined over the temperature range of $600-723 \mathrm{~K}$. The values obtained here are discussed in comparison to those from literature.
\end{abstract}

\section{Introduction}

During the last years a number of compilations have been published on experimental transport properties of single and mixed molten salts, e.g., on electrical conductivities, thermal conductivities, viscosities and diffusion coefficients [1, 2]. However, the agreement between the results of different diffusion studies is poor and the necessity of a critical evaluation of the results of independently completed studies becomes evident (cf. Ref. [2]).

The scope of the present work is a careful determination of some interdiffusion coefficients in molten salts and their comparison with results obtained with various methods. During the last two decades several investigations on the diffusion in molten alkali nitrate mixtures have been performed [3-16]. Besides radio-active tracers, the capillary, paper strip, interferometric and gravimetric methods were used. Therefore studies on alkali nitrate mixtures seemed fit for our purpose.

We have chosen the gravimetric method with a porous frit. The advantage of this method is that it allows a continuous registration, thus providing a very large number of observations in each run and with rather simple apparatus. Moreover, if used as a relative method, many systematic errors will be eliminated or at least greatly reduced. Contrary to other methods no radio-active tracers or time-consuming chemical analysis have to be used.

* Present address: Akzo Research, Velperweg 76, 6824 BM Arnhem, Netherlands.

** Reprint requests to Prof. Dr. J. A. A. Ketelaar, Markeloseweg 91, 7461 PB Rijssen, Netherlands.
In this method a porous frit is filled with a solution of known concentration. After complete filling the frit is transferred to a large volume of another solution with a different concentration. The exchange of the contents of the frit with the bath solution is followed by observing the weight change.

The frit is a cylinder with parallel faces (radius $R$, thickness $2 L$ ). For the ideal case with flow perpendicular to the surfaces, constant concentration at the surface and absence of inert material the equation for the weight as a function of time becomes [19]

$$
\begin{aligned}
w(t)= & w(\infty)+\frac{64 h L\left(c_{1}-c_{0}\right)}{\pi} \\
& \cdot \sum_{n=0}^{\infty} \sum_{m=0}^{\infty} \frac{1}{(2 n+1)^{2} a_{m}^{2}} \exp (-u t) \\
u= & D\left(a_{m}^{2}+\frac{(2 n+1)^{2} \pi^{2}}{4 L^{2}}\right),
\end{aligned}
$$

with

where $w(\infty)$ is the weight at infinite time, $c_{1}$ the initial concentration in the frit, $c_{0}$ the constant concentration of the outer solution, $h$ the proportionality factor of the concentration-density relation, $D$ the diffusion coefficient and the $a_{m}$ are roots of the equation $J_{0}\left(R a_{m}\right)=0$ with $J_{0}$ the Bessel function of the first kind of order zero.

By use of (1) we did include the radial diffusion, contrary to what has been done formerly, where only the axial diffusion was considered [e.g., 3, 11, 17, 18, 18 a]. The contribution from radial diffusion is rather large, e.g. for $R / 2 L=2.5$, as in our case, this radial flow reaches $20-25 \%$; only for values of $R / 2 L>17$ this drops below $1 \%$. However, in rela- 
tive measurements the effect of neglecting radial diffusion is greatly reduced.

Equation (1), a set of exponential functions, is to be fitted to the observed weight changes. In our computer program REG [20a] the first four $n$-terms and the first nine $m$-terms in the summation have been used to fit by a non-linear regression analysis the calculated curve to the experimental one.

Given the sources of error connected with absolute measurements we have preferred to perform relative measurements. Here the diffusion measurement is replicated with an aqueous solution of which the diffusion coefficient is known, e.g., $0.5 \mathrm{~N} \mathrm{KCl}$. In this way systematic errors, e.g. the end- or $L$-effect will largely be eliminated for liquids with comparable viscosities and diffusion coefficients [21].

As has been shown by Wall and Wendt [18a], the diffusion coefficient found will be very close to that for the outer solution (except for the very beginning).

\section{Description of the Experiment}

A porous frit, impregnated with a solution of definite concentration, is attached by a thin platinum wire to an analytical balance and is suspended in a large thermostated bath of a solution of different concentration. The diffusion is followed by recording the apparent weight of the frit as a function of time.

We have used an electronic balance (Mettler HE 20). The weight change was followed in two ways:

1) directly by a recorder, Kipp BD 8 ,

2) by means of an $\mathrm{AC} / \mathrm{DC}$ converter (integration time $400 \mathrm{~ms}$ ) the analogue signal of the balance is converted to a digital signal, which at first is printed every minute and later every 10 minutes for a total of about $2 \mathrm{~h}$. The print-out is used as input for the computer calculation of the diffusion coefficient.

The concentration of the outer solution can be assumed to be constant throughout the experiment [45]. An effective diffusion coefficient can be calculated from the weight versus time curve. The experimental technique has been described in detail elsewhere [20].

\section{Results for Aqueous Solutions}

In previous investigations $[11,18,22]$ and also in our first experiments with the porous frit method the frit was calibrated by measuring the diffusion in only one aqueous solution with a well known diffusion coefficient $D_{\text {cal }}$ (e.g., $\mathrm{KCl}, \mathrm{NaCl}$ ). The calibration of the porous frit was done by plotting $\ln [w(t)-w(\infty)]$ vs. $t$. Except for small times this plot is a straight line with a slope $S\left(=\pi^{2} D_{\text {cal }} / 4 L^{2}\right)$. In a similar measurement of another solution or of a molten salt mixture a slope $S^{\prime}$ was obtained and the diffusion coefficient $D$ of this solution or melt was calculated with the aid of the relation

$$
D / S^{\prime}=D_{\text {cal }} / S .
$$

Although the results were comparable with those obtained with other methods the above procedure has some disadvantages:

1) as the measured slope is very sensitive to small variations in the value used for the final weight, this weight has to be known very accurately. External influences as evaporation, variation of the room temperature, drift of the balance will lower this accuracy. Moreover in the above calculation no correction for the unequal statistical weights of the data points has been made.

2) the radial diffusion is not taken into account.

3) it has been assumed that the calibration coefficient does not vary with the diffusion coefficient.

4) the error caused by a slight disturbance of the diffusion, for instance by adsorption or turbulence, may not be recognized.

The first two disadvantages have been eliminated by using another kind of data processing. Since the functional form of the weight as a function of time is explicitly known (1), a non-linear fit to the experimental curve can be made. In this way the statistical weight of the data points, contributing to the calculated parameters, will be equal. Moreover a disturbance after a long time will no longer influence the calibration coefficient, since the accuracy of the curve fit does not depend on the accuracy of the final weight anymore.

The other two disadvantage have been solved by calibrating the frit with a set of solutions of different substances, instead of a single one. Furthermore a calibration based on more data points will increase the precision of the experimental diffusion 
coefficient of the molten salt since these are now obtained by interpolation instead of extrapolation. The set of calibration solutions has been selected for a variety of diffusion coefficients and of chemical behaviour. At the same time the solute has to satisfy a number of experimental conditions:

1) the diffusion coefficient has to be well known over a large range of concentrations,

2) the density has to be a linear function of the concentration, at least within the range used,

3 ) the density difference between bath and frit solution must not be too small,

4) the diffusion coefficient has by preference to be constant within the concentration range used.

The application of the curve fitting to the full equation (1) by the program REG (page 248) [20 a] leads to a value for

$$
" S "=\pi^{2} D / 4 L^{2}
$$

(in quotation marks to distinguish it from the slope $S$ in (2) obtained from the straight line of $\ln [w(t)$ $-w(\infty)]$ vs. $t$, if small times are omitted) which will be called the slope factor.

In Fig. 1 we have plotted the slope factor " $S$ " found as a function of the diffusion coefficient $D$ from literature. If $D / S^{\prime}$ would be equal for all solutions the slope factor should be a linear function

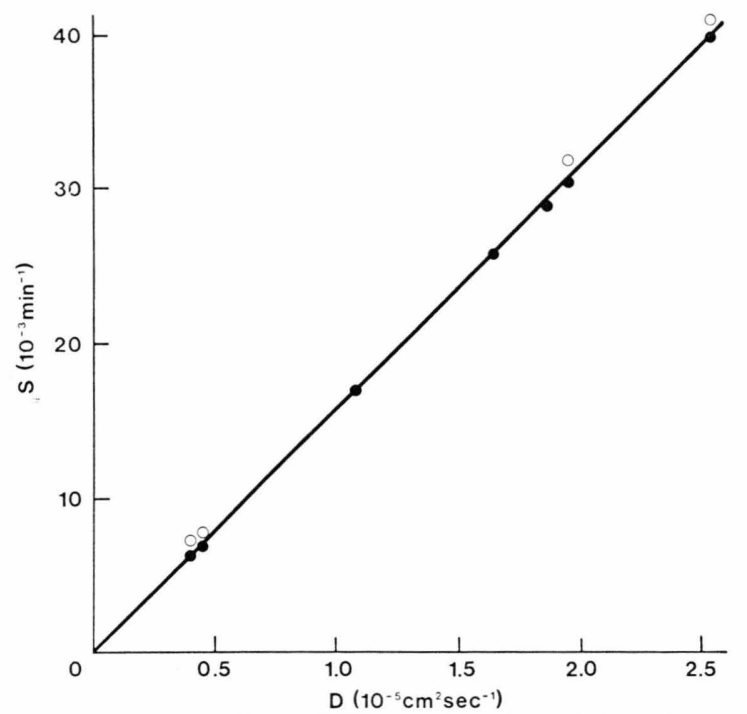

Fig. 1. Calc. slope factor " $S$ " as a function of the diffusion coefficients $D$. $\bigcirc$ Uncorrected, Results corrected for adsorption. For the literature values of $D$ see Table 1. (The three points for the chlorides are represented by full circles only, as no corrections for adsorptions are necessary.) through the origin. This is not the case as a least squares line through the experimental points does have a small positive intercept on the " $S$ "-axis.

It is known that adsorption may play a role in diffusion of gases and solutions through porous media, which necessarily have a large surface in relation to the volume.

Indeed other measurements [23-25] confirm a specific adsorption of the larger bromide and iodide anions but not of the chloride ion on glass and quartz. Although the number of adsorbed layers is small $(<5)$, adsorption will influence the weight change of the frit due to the large surface area of the frit of about $1 \mathrm{~m}^{2}$ in relation to a free volume of only $550 \mathrm{~mm}^{3}$.

Wilson [26] and Crank [27] have solved the diffusion equation for the general case, in which the rates of diffusion and reaction are comparable. In our diffusion experiments the rate of reaction is slow compared with that of diffusion.

When we compare this expression with the one for the ideal case (1) we see that the influence of the adsorption reaction on the diffusion results only in an extra term in the exponent (at least in case the reaction rate constant $k$ is small with regard to the diffusion rate constant $u$ ).

The correction for adsorption in our calculations is a simple adjustment of the partial derivatives of $w(t)$. The experimental slope factor " $S$ " is now

$$
" S "=\left(\pi^{2} D / 4 L^{2}\right)+k \text {. }
$$

If we correct the values found for " $S$ " for the bromides and iodides with the value of $k$ then the corrected values

$$
\text { " } S_{\text {corr }} "=\pi^{2} D / 4 L^{2}
$$

should fall, with those for the chlorides, on the same straight line through the origin (Figure 1). This is indeed the case for the least squares line through the corrected points. The remaining small negative intercept with the ordinate is completely within the limits of error. Experimental adsorption rate constants, obtained from tracer adsorption rate measurements (Table 1) were used for these corrections.

In Table 1 literature values of the interdiffusion coefficient are compared with the values found in this work from the slope factor " $S_{\text {corr }}$ ". The "uncorrected' values in the table are the values found by using (2) with a single point of reference, the value of the slope factor for $\mathrm{KCl}$ at $298 \mathrm{~K}$. The correspondence between the corrected and the literature 
Table 1. Experimental results for the interdiffusion coefficients $D$ in various aqueous solutions (quartz frits).

\begin{tabular}{|c|c|c|c|c|c|c|c|}
\hline \multirow[t]{2}{*}{ Solute } & \multicolumn{2}{|c|}{ Concentration } & \multirow[t]{2}{*}{ Temp. } & \multicolumn{3}{|c|}{ Interdiffusion coefficient } & \multirow[t]{2}{*}{ Ref. } \\
\hline & $\begin{array}{l}\text { frit } \\
{[\mathrm{mol} / 1]}\end{array}$ & $\begin{array}{l}\text { bath } \\
{[\mathrm{mol} / \mathrm{l}]}\end{array}$ & & $\begin{array}{l}\text { uncorrected }^{\mathrm{a}} \\
{\left[10^{-5} \mathrm{~cm}^{2} \mathrm{~s}^{-1}\right]}\end{array}$ & $\begin{array}{l}\text { corrected for } \\
\text { adsorption } \\
{\left[10^{-5} \mathrm{~cm}^{2} \mathrm{~s}^{-1}\right]}\end{array}$ & $\begin{array}{l}\text { litt. } \\
\text { value } \\
{\left[10^{-5} \mathrm{~cm}^{2} \mathrm{~s}^{-1}\right]}\end{array}$ & \\
\hline $\mathrm{Bu}_{4} \mathrm{NBr}$ & 0.1 & 0.5 & 298 & $0.488 \pm 0.005$ & $0.408 \pm 0.008$ & 0.390 & {$[28,29]$} \\
\hline $\mathrm{Bu}_{4} \mathrm{NBr}$ & 1.0 & 0.5 & 298 & $0.500 \pm 0.041$ & $0.450 \pm 0.023$ & 0.436 & {$[28,29]$} \\
\hline $\mathrm{BaCl}_{2}$ & 0.0 & 0.5 & 295 & $1.080 \pm 0.028$ & $1.080 \pm 0.028$ & 1.077 & {$[30]$} \\
\hline $\mathrm{KCl}^{-}$ & 0.1 & 0.5 & 293 & $1.628 \pm 0.011$ & $1.628 \pm 0.011$ & 1.626 & {$[31-33]$} \\
\hline $\mathrm{KCl}$ & 0.1 & 0.5 & 298 & 1.848 & 1.848 & 1.848 & {$[31-33]$} \\
\hline KI & 0.1 & 0.5 & 298 & $2.045 \pm 0.011$ & $1.952 \pm 0.007$ & 1.937 & {$[34]$} \\
\hline KI & 3.0 & 3.5 & 298 & $2.641 \pm 0.022$ & $2.561 \pm 0.0122 .521$ & {$[34]$} & \\
\hline
\end{tabular}

a Based on $\mathrm{KCl}$ at $298 \mathrm{~K}$ as only point of reference.

b For bromides and iodides corrected for adsorption $\left(k=2.5\left[10^{-5} \mathrm{~s}^{-1}\right]\right)[23,25]$.

values is complete within the small limits of error for both sets.

\section{Results for Molten Salts}

Although the first applications of the porous glass frit diffusion with the gravimetric method, known in literature, have been made in aqueous solutions [18], measurements in molten salts [3] have been performed too. The interdiffusion coefficient of electrolyte solutions, measured in this way, did agree rather well with those obtained with other measuring methods. Also in this work very good results were obtained in aqueous solutions with the improved gravimetric method.

The gravimetric method has been applied formerly for the determination of the interdiffusion coefficient in molten salts by Sjöblom [3], Behn [35] and Andreasson et al. [11]. However, here the results were at first less promising than with aqueous solutions. The substitution of the glass frit, first used by Sjöblom [3] and by us, by a quartz frit [11] resulted in a great improvement [46]. Otherwise the measurements in molten salts were made using the same experimental procedures and following the same methods of data production and data processing as described above and as used with electrolyte solutions.

The gravimetric method as elaborated in this work has proven to be a relatively simple, accurate and reliable method for determining diffusion coefficients in both solutions and molten salts.

For several alkali nitrate mixtures the interdiffusion coefficients have been determined over a range of temperatures.
The experimental results can be represented very well, at least in the relatively small temperature range available, by the Arrhenius type equation

$$
D=D_{0} \exp \left(-H_{\mathrm{D}} / R T\right)
$$

For all systems the parameters $D_{0}$ and $H_{\mathrm{D}}$ have been calculated from the values of $D$ at each temperature with a computer program using a nonlinear regression technique. The diffusion coefficient at any temperature may be calculated back from (6) with the parameters obtained. The error of such an interpolated value is given by the reduced sum of residuals.

\section{A) The interdiffusion coefficient in the system $\mathrm{KNO}_{3}-\mathrm{CsNO}_{3}$}

In Table 2 the experimental results for the interdiffusion in the system $\mathrm{KNO}_{3}-\mathrm{CsNO}_{3}$ at the molar fractions $x_{\mathrm{Cs}}=0.0$ and $x_{\mathrm{Cs}}=0.1$ are given as a function of temperature. Each interdiffusion coefficient has been calculated from 70 data points of the weight-time curve of each experimental run. The duration of the experiment is equal to 124 minutes. The indicated error in the interdiffusion coefficient, the $95 \%$ confidence limit, is a composite of the error due to the inaccuracy in the calibration and of the error due to the inaccuracy in a single molten salt experimental run. The internal consistency of the experimental data is shown in Table 2. The numerical values of the two diffusion coefficients at $724 \mathrm{~K}$ lie within both error limits.

Some experimental data of the interdiffusion in nearly pure $\mathrm{KNO}_{3}$ are known. Moreover the tracer diffusion of $\mathrm{Cs}^{+}$in $\mathrm{KNO}_{3}$, which is equal to the 
Table 2. Interdiffusion coefficients in the system $\mathrm{KNO}_{3}-$ $\mathrm{CsNO}_{3}$ as a function of temperature.

\begin{tabular}{lll}
\hline$T[\mathrm{~K}]$ & $D\left[10^{-5} \mathrm{~cm}^{2} \mathrm{~s}^{-1}\right]$ & \\
& $x_{\mathrm{Cs}}=0.0$ & $x_{\mathrm{Cs}}=0.1$ \\
621.35 & $1.442 \pm 0.011$ & $1.446 \pm 0.009$ \\
636.05 & $1.598 \pm 0.010$ & $1.573 \pm 0.008$ \\
650.75 & $1.752 \pm 0.009$ & $1.727 \pm 0.008$ \\
665.55 & $1.917 \pm 0.010$ & $1.903 \pm 0.008$ \\
680.25 & $2.089 \pm 0.013$ & $2.041 \pm 0.012$ \\
695.05 & $2.277 \pm 0.023$ & $2.270 \pm 0.023$ \\
709.75 & $2.471 \pm 0.038$ & $2.427 \pm 0.034$ \\
724.55 & $2.653 \pm 0.055$ & $2.627 \pm 0.053$ \\
739.25 & $2.607 \pm 0.051$ & $2.567 \pm 0.047$ \\
& $2.825 \pm 0.076$ & $2.850 \pm 0.079$ \\
\hline
\end{tabular}

interdiffusion in pure $\mathrm{KNO}_{3}$, has been measured too.

In Fig. 2 our results of the interdiffusion coefficient together with those obtained by others, are plotted $v$ s. the reciprocal temperature.

The parameters of the Arrhenius equation (6), $D_{0}$ and $H_{\mathrm{D}}$, from our results as well as those from other authors are given in Table 3.

As can be seen from Fig. 2, the interdiffusion coefficients obtained by the interferometric method by Arvidsson et al. [36] and by Odawara et al. [37] are about $30 \%$ lower than our results, but especially those from Arvidsson et al. show an enormous spread, indicating a low precision. The agreement between our results and those obtained with the paperstrip method [38] is very good. However the temperature dependence is almost the same for all measurements as can be expected from the elimination of most systematic errors of each method and from the averaging effect on accidental errors.

A comparison between the interdiffusion in pure $\mathrm{KNO}_{3}$ and in the mixture $0.1 \mathrm{CsNO}_{3}-0.9 \mathrm{KNO}_{3}$ shows that the former is somewhat larger (about $1.5 \%)$. Application of a linear dependence of the

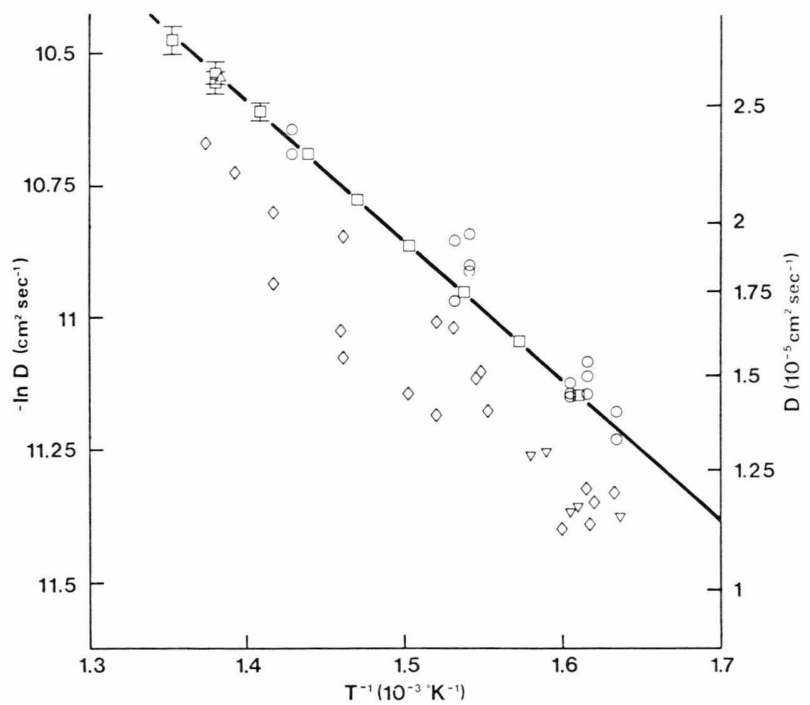

Fig. 2. The temperature dependence of the interdiffusion coefficient $D$ in the system $\mathrm{CsNO}_{3}-\mathrm{KNO}_{3}\left(x_{\mathrm{Cs}}=0.0\right)$. $\square$, present work; $\diamond$, Ref. [36]; $\bigcirc$, Ref. [38]; $\nabla$, Ref. [37].

interdiffusion on the mole fraction

$$
D=x_{1} D_{2}+\left(1-x_{1}\right) D_{1}
$$

to the experimental data of Honig [5, 39] for this system confirms this trend for the interdiffusion coefficient as a function of the concentration.

\section{B) The interdiffusion coefficient in the systems $\mathrm{NaNO}_{3}-\mathrm{AlkNO}_{3}$ with $\mathrm{Alk}=\mathrm{K}, \mathrm{Rb}$ and $\mathrm{Cs}$}

Of all molten nitrate mixtures the interdiffusion in the system $\mathrm{NaNO}_{3}-\mathrm{CsNO}_{3}$ has been studied most. Moreover several measuring methods have been used, so a critical discussion of the experimental results will be possible.

In the system $\mathrm{NaNO}_{3}-\mathrm{KNO}_{3}$ several tracer diffusion measurements at different mole fractions have been performed. Because of this, and also to see

Table 3. Parameters of the Arrhenius equation, $D_{0}$ and $H_{\mathrm{D}}$, for the system $\mathrm{KNO}_{3}-\mathrm{CsNO}_{3}$.

\begin{tabular}{|c|c|c|c|c|c|c|}
\hline $\begin{array}{l}D_{0} \cdot 10^{5} \\
{\left[\mathrm{~cm}^{2} \mathrm{~s}^{-1}\right]}\end{array}$ & $\begin{array}{l}H_{\mathrm{D}} \\
{[\mathrm{cal} / \mathrm{mol}]}\end{array}$ & $\begin{array}{l}\text { Temp. Range } \\
{[\mathrm{K}]}\end{array}$ & $\begin{array}{l}D(T=623) \cdot 10^{5} \\
{\left[\mathrm{~cm}^{2} \mathrm{~s}^{-1}\right]}\end{array}$ & $\begin{array}{l}\text { Measuring } \\
\text { method }^{b}\end{array}$ & Reference & $x_{\mathrm{Cs}}$ \\
\hline 73.2 & 5070 & $612-728$ & 1.22 & 1 & Arvidsson [36] & 0.0 \\
\hline \multirow[t]{2}{*}{133.0} & 5556 & $612-700$ & 1.50 & 2 & Odawara [38] & 0.0 \\
\hline & & $611-633^{\mathrm{a}}$ & 1.20 & 1Odawara [37] & & \\
\hline $101.4 \pm 2.6$ & $5248 \pm 34$ & $621-739$ & $1.463 \pm 0.002$ & 3 & this work & 0.0 \\
\hline $94.1 \pm 6.3$ & $5166 \pm 88$ & $621-739$ & $1.451 \pm 0.004$ & 3 & this work 0.1 & \\
\hline
\end{tabular}

a Temperature range too small for reliable determination of the temperature dependence.

b $1=$ Interferometric, 2 = Paper strip, $3=$ Gravimetric. 
whether the small difference between the density of the melt in the frit and in the bath was sufficient to obtain reliable results, we have also measured the interdiffusion coefficients in this system.

The difference in the mole fraction of the two melts has to be as large as possible in order to yield an acceptable signal to noise ratio, but on the other hand the differences may not be too large, otherwise the mole fraction, at which the interdiffusion is measured, will be ill-defined. We have chosen a difference in the mole fractions of about 0.3 , which corresponds to about $1 / 3$ of the weight difference between the initial and final weight in the $\mathrm{KCl}$ aqueous solution measurements. Due to the considerable noise and the small weight difference some hundred runs had to be made to obtain reasonable results for the interdiffusion coefficients.

The interdiffusion coefficient as a function of temperature has been measured at three different mole fractions. The results for the calculated parameters of the Arrhenius equation, $D_{0}$ and $H_{\mathrm{D}}$, are given in Table 4.

In the limiting cases $x_{\mathrm{Na}} \rightarrow 0$ and $x_{\mathrm{K}} \rightarrow 0$ the observed results may be compared with the results for tracer diffusion of other authors. However for mixtures no interdiffusion coefficients are available.
With the assumption of the validity of (7), the interdiffusion coefficient at any mole fraction may be calculated with the aid of the two tracer diffusion coefficients.

\section{Discussion}

Comparison of the interdiffusion coefficients for $\mathrm{Alk}=\mathrm{Rb}$ at $623 \mathrm{~K}$ shows a large difference between the results of Behn [11, 35] and our results, both using the gravimetric method. Although the measuring method used by Behn is in principle the same as we have used, several rather important differences between the two measuring procedures exist. Therefore the systematic deviation in the interdiffusion coefficients is very likely due to the influence of these differences, which are:

1) unlike Behn, who has neglected the radial diffusion, we have included explicitly the radial diffusion in our calculations of the interdiffusion coefficients. For this neglect his value for the "slope factor" and thus for the diffusion coefficient could come out up to $25 \%$ too high.

2) we have used a non-linear regression analysis for the calculation of the diffusion coefficient from the experimental weight-time curves, while

Table 4. Parameters of the Arrhenius equation, $D_{0}$ and $H_{\mathrm{D}}$, for the system $\mathrm{NaNO}_{3}-\mathrm{AlkNO}_{3}$.

\begin{tabular}{|c|c|c|c|c|c|c|}
\hline $\begin{array}{l}D_{0} \cdot 10_{5} \\
{\left[\mathrm{~cm}^{2} / \mathrm{sec}\right]}\end{array}$ & $\begin{array}{l}H_{\mathrm{D}} \\
{[\mathrm{cal} / \mathrm{mol}]}\end{array}$ & $\begin{array}{l}\text { Temp. Range } \\
{[\mathrm{K}]}\end{array}$ & $\begin{array}{l}D(623) \cdot 10^{5} \\
{\left[\mathrm{~cm}^{2} / \mathrm{sec}\right]}\end{array}$ & $\begin{array}{l}\text { Measuring } \\
\text { method }^{\text {a }}\end{array}$ & Reference & $x_{\mathrm{Alk}}$ \\
\hline \multicolumn{7}{|c|}{$\mathrm{Alk}=\mathrm{Cs}$} \\
\hline $\begin{array}{r}32.4 \\
85.0 \\
64.3 \\
114.2 \\
100.7 \\
82.2 \pm 6.1 \\
79.4 \pm 8.7\end{array}$ & $\begin{array}{l}3530 \\
4740 \\
4690 \\
5062 \\
4670 \\
4671 \pm 92 \\
4626 \pm 136\end{array}$ & $\begin{array}{l}624-668 \\
603-722 \\
581-666 \\
584-700 \\
623-693 \\
598-725 \\
598-725\end{array}$ & $\begin{array}{l}1.88 \\
1.85 \\
1.46 \\
1.91 \\
2.31 \\
1.890 \pm 0.005 \\
1.893 \pm 0.007 \\
\quad \mathbf{A l k}=\mathbf{R b}\end{array}$ & $\begin{array}{l}4 \text { Koster }[40] \\
2 \\
1 \\
2 \\
4 \\
3 \\
3\end{array}$ & $\begin{array}{l}0.0 \\
\text { Kwak [41-43] } \\
\text { Arvidsson [36] } \\
\text { Odawara [38] } \\
\text { Nagarajan [44] } \\
\text { this work } \\
\text { this work }\end{array}$ & $\begin{array}{l}0.0 \\
0.0 \\
0.0 \\
0.0 \\
0.0 \\
0.1\end{array}$ \\
\hline $\begin{array}{l}32.1 \\
- \\
69.0 \\
50.0 \\
199.9 \pm 71.7 \\
134.6 \pm 40.9\end{array}$ & $\begin{array}{l}3670 \\
- \\
4170 \\
3860 \\
5780 \pm 435 \\
5355 \pm 372\end{array}$ & $\begin{array}{l}582-668 \\
- \\
593-637 \\
595-635 \\
597-623 \\
597-640\end{array}$ & $\begin{array}{l}1.66 \\
1.90 \\
2.38 \\
2.21 \\
1.877 \pm 0.010 \\
1.782 \pm 0.013\end{array}$ & $\begin{array}{l}1 \\
2 \\
5 \\
3 \\
3 \\
3\end{array}$ & $\begin{array}{l}\text { Arvidsson [36] } \\
\text { Odawara [38] } \\
\text { Behn }[11,35] \\
\text { Behn }[11,35] \\
\text { this work } \\
\text { this work }\end{array}$ & $\begin{array}{l}0.0 \\
0.0 \\
0.0 \\
0.0 \\
0.0 \\
0.1\end{array}$ \\
\hline \multicolumn{7}{|c|}{$A l k=K$} \\
\hline $\begin{array}{c}73.2 \pm 70.5 \\
162.6 \pm 195.7 \\
292.5 \\
217.1 \pm 172.4\end{array}$ & $\begin{array}{l}4431 \pm 1227 \\
5536 \pm 1590 \\
6237 \\
5913 \pm 1071\end{array}$ & $\begin{array}{l}619-722 \\
637-726 \\
621-688 \\
637-726\end{array}$ & $\begin{array}{l}2.043 \pm 0.064 \\
1.859 \pm 0.101 \\
1.90 \\
1.831 \pm 0.064\end{array}$ & $\begin{array}{l}3 \\
3 \\
1 \\
3\end{array}$ & $\begin{array}{l}\text { this work } \\
\text { this work } \\
\text { Arvidsson [36] } \\
\text { this work }\end{array}$ & $\begin{array}{l}0.0 \\
0.7 \\
1.0 \\
1.0\end{array}$ \\
\hline
\end{tabular}

a 1 = Interferometric, 2 = Paper strip, 3 = Gravimetric, $4=$ Capillary, $5=$ Porous frit, tracer. 
Behn used a linear least squares fit of the function $\ln [w(t)-w(\infty)]$.

The latter way of calculation will be less accurate than the former one, since it needs the knowledge of the final weight $w(\infty)$, which in general is rather inaccurate but has a high statistical weight, and moreover it does not make use of whole experimental curve, for the first part is neglected though there the rate of diffusion is high.

3) we have calibrated our frits with a set of solutions of which the diffusion coefficient covers a large range. Behn has calibrated his frits with a single diffusion coefficient $(0.5 \mathrm{~N} \mathrm{KCl})$.

[1] G. J. Janz et al., Physical Properties Data compilation relevant to energy storage, Molten Salts, N.S.R.D.S.N.B.S., 61 (1) (1978), 61 (2) (1979).

[2] G. J. Janz and N. P. Bansal, J. Phys. Chem. Ref. Data 11, 505 (1982)

[3] C. A. Sjöblom, Z. Naturforsch. 20 a, 1572 (1965).

[4] F. Lantelme and M. Chemla, Electrochim. Acta 11, 1023 (1966).

[5] E. P. Honig and J. A. A. Ketelaar, Trans. Faraday Soc. 62, 190 (1966).

[6] S. Forcheri and V. Wagner, Z. Naturforsch. 22 a, 1171 (1967)

[7] J. A. A. Ketelaar and J. C. Th. Kwak, Trans. Faraday Soc. 65, 139 (1969).

[8] J. E. L. Bowcott and B. A. Punkett, Electrochim. Acta 14, 363 (1969).

[9] S. Sternberg and C. Herdlicka, Rev. Roum. Chim. 14, 991 (1969).

[10] K. Kawamura, Denki Kagaku 38, 12 (1970).

[11] D. Andreasson, A. Behn, and C.-A. Sjöblom, Z. Naturforsch. 25a, 700 (1970).

[12] G.-A. Mazzocchin and G. Schiavon, J. Electroanal. Chem. 39, 367 (1972)

[13] S. Zuca and M. Constantinescu, Z. Naturforsch. 28a, 51 (1973).

[14] J. Richter, J. Chem. Eng. Data 18, 400 (1973).

[15] I. Okada and S. E. Gustafsson, Z. Naturforsch. 33 a, 447 (1978).

[16] O. Odawara, J. C. Th. Kwak, and J. A. A. Ketelaar, Z. Naturforsch. 35 a, 423 (1980).

[17] S. Djordjevic and G. J. Hills, Trans. Faraday Soc. 56, $269(1960)$

[18] F. T. Wall, P. F. Grieger, and C. W. Childers, J. Amer. Chem. Soc. 74, 3562 (1952).

[18a] F. T. Wall and R. C. Wendt, J. Phys. Chem. 62, 1581 (1958).

[19] H. S. Carslaw and J. C. Jaeger, Conduction of Heat in Solids, 2nd ed., Oxford Univ. Press, New York 1959.

[20] F. van der Graaf, Thesis, Amsterdam 1981.

[20a] See [20] for a listing of program REG.

[21] J. Koster and J. A. A. Ketelaar, J. Chim. Phys. 66, 171 (1969).

[22] A. E. Marcinowsky, F. Nelson, and K. A. Kraus, J. Phys. Chem. 69, 303 (1965).
When we consider the effect of these important differences, the results obtained with our procedure should be more accurate (due to the second and third difference) and lower (the first difference) than the results obtained by Behn's procedure.

Thus despite of the small weight difference between initial and final state, we were able to obtain reliable results, and this implies that the improved gravimetric method of the porous frit diffusion may be used for the determination of the interdiffusion coefficient in almost any molten salt mixture or any binary solution in general.

[23] H. J. Arnikar, E. A. Daniels, and S. V. Kulkarni, J. Indian Chem. Soc. 49, 649 (1972).

[24] O. P. Mehta, Indian J. Chem. 12, 315 (1974).

[25] B. B. Prasad, Proc. 3rd Nucl. Radiat. Chem. Symp. $1967,376$.

[26] A. H. Wilson, Phil. Mag. 39, 48 (1948).

[27] J. Crank, Phil. Mag. 39, 362 (1948).

[28] H. Kim, A. Revzin, and L. J. Gosting, J. Phys. Chem. 77, 2567 (1973).

[29] C. N. Pepela, B. J. Steel, and P. N. Dunlop, J. Amer. Chem. Soc. 92, 6743 (1970).

[30] V. Vitagliano and P. A. Lyons, J. Amer. Chem. Soc. 78, 1549 (1956).

[31] H. S. Harned and R. L. Nutall, J. Amer. Soc. 71, 1460 (1949).

[32] L. J. Gosting, J. Amer. Chem. Soc. 72, 4418 (1950).

[33] R. H. Stokes, J. Amer. Chem. Soc. 72, 2243 (1950); ibid. 73, 3527 (1951).

[34] P. J. Dunlop and R. H. Stokes, J. Amer. Chem. Soc. 73, 5456 (1951).

[35] A. Behn, Thesis, Gothenburg 1973.

[36] T. E. G. Arvidsson, S. A. Afsenius, and S. E. Gustafsson, J. Chem. Phys. 53, 2621 (1970).

[37] O. Odawara, I. Okada, and K. Kawamura, Z. Naturforsch. 34 a, 504 (1979).

[38] O. Odawara, J. C. Th. Kwak, and J. A. A. Ketelaar, Z. Naturforsch. 35a, 423 (1980)

[39] E. P. Honig, Thesis, Amsterdam 1964.

[40] J. Koster and J. A. A. Ketelaar, Trans. Faraday Soc. 62, 171 (1969).

[41] J. C. Th. Kwak, Thesis, Amsterdam 1967.

[42] J. A. A. Ketelaar and J. C. Th. Kwak, J. Phys. Chem. 71, 1149 (1967)

[43] J. C. Th. Kwak and J. A. A. Ketelaar, J. Phys. Chem. 73, 73 (1969).

[44] M. K. Nagarajan and J. O. M. Bockris, J. Phys. Chem. 70, 1854 (1966).

[45] A small vertical temperature coefficient of about $0.4 \mathrm{~K} \mathrm{~cm}^{-1}$ ensures a small and constant $\Delta L$-effect and it will also bring on a rapid disappearance of the outside layer of frit solution, both by a slight convective flow in the bath.

[46] Very probably due to the absence of ion exchange with the quartz frit. 